\title{
Publisher Correction to: Design and Simulation of a Crash Energy Absorption System Integrated with Magneto-Rheological Absorber
}

\author{
Pavan Kumar Archakam ${ }^{1}$. Sreekumar Muthuswamy ${ }^{1}$ (D)
}

Published online: 17 June 2021

(c) Krishtel eMaging Solutions Private Limited 2021

\section{Publisher Correction to: Journal of Vibration Engineering \& Technologies https://doi.org/ 10.1007/s42417-021-00318-6}

The publication of this article unfortunately contained mistakes. The corresponding author was incorrect. The corresponding author of this article is Sreekumar Muthuswamy.

The original article has been corrected.

Publisher's Note Springer Nature remains neutral with regard to jurisdictional claims in published maps and institutional affiliations.

The original article can be found online at https://doi.org/10.1007/ s42417-021-00318-6.

Sreekumar Muthuswamy msk@iiitdm.ac.in

1 Centre for AI, IoT, and Robotics, Department of Mechanical Engineering, Indian Institute of Information Technology, Design and Manufacturing, Kancheepuram, Chennai 600127, India 